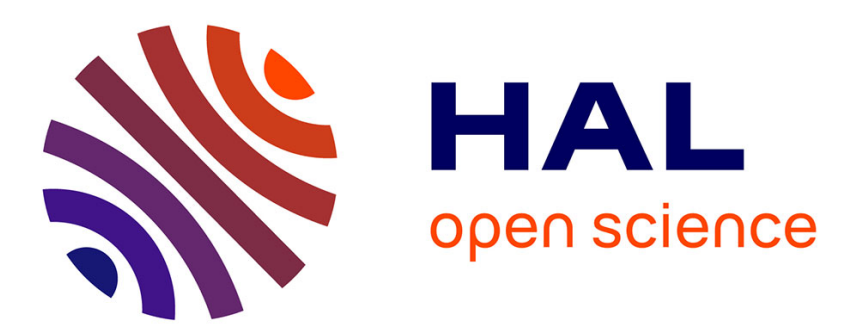

\title{
Using spectrophotometric titrations to characterize humic acid reactivity at environmental concentrations
}

\author{
Noémie Janot, Pascal E. Reiller, G.V. Korshin, Marc F. Benedetti
}

\section{To cite this version:}

Noémie Janot, Pascal E. Reiller, G.V. Korshin, Marc F. Benedetti. Using spectrophotometric titrations to characterize humic acid reactivity at environmental concentrations. Environmental Science and Technology, 2010, 44 (17), pp.6782-6788. 10.1021/es1012142 . cea-00512354

HAL Id: cea-00512354

https://hal-cea.archives-ouvertes.fr/cea-00512354

Submitted on 23 Sep 2021

HAL is a multi-disciplinary open access archive for the deposit and dissemination of scientific research documents, whether they are published or not. The documents may come from teaching and research institutions in France or abroad, or from public or private research centers.
L'archive ouverte pluridisciplinaire HAL, est destinée au dépôt et à la diffusion de documents scientifiques de niveau recherche, publiés ou non, émanant des établissements d'enseignement et de recherche français ou étrangers, des laboratoires publics ou privés. 


\title{
Using spectrophotometric titrations to characterize hu- mic acid reactivity at environmental concentrations
}

\author{
Noémie Janot ${ }^{1,2}$, Pascal E. Reiller ${ }^{2}$, Gregory V. Korshin ${ }^{3}$, Marc F. Benedetti, ${ }^{1, *}$ \\ ${ }^{1}$ Laboratoire de Géochimie des Eaux, Université Paris Diderot, IPGP UMR CNRS 7154, 75025 Paris, Cedex 13, France, \\ ${ }_{2}^{2}$ Commissariat à l'Énergie Atomique, CE Saclay, CEA/DEN/DANS/DPC/SECR, Laboratoire de Spéciation des Radionu- \\ cléides et des Molécules, Bâtiment 391 PC 33, F-91191 Gif-sur-Yvette CEDEX, France. \\ ${ }^{3}$ Department of Civil and Environmental Engineering, University of Washington, Seattle, Washington 98195-2700, United \\ States. \\ * corresponding author e-mail : benedetti@ipgp.fr
}

\begin{abstract}
Potentiometric titration is a common method to characterize dissolved organic matter (DOM) reactivity. Due to the sensitivity of $\mathrm{pH}$ electrodes, it is necessary to work with very high DOM $(>1 \mathrm{~g} / \mathrm{L})$ concentrations that are unrealistic compared to those found in natural waters $(0.1$ to $100 \mathrm{mg} /$ L). To obtain proton binding data for concentrations closer to environmental values, spectroscopic titration method is a viable alternative to traditional potentiometric titrations. Spectrophotometric titrations and UV-visible spectra of a diluted solution of purified Aldrich humic acid $\left(5 \mathrm{mg} \mathrm{DOC}_{\mathrm{L}} / \mathrm{L}\right)$ are used to estimate changes in proton binding moieties as function of $\mathrm{pH}$ and ionic strength after calculation of differential absorbance spectra variations. After electrostatic correction of spectrophotometric data, there is a linear operational correlation between spectrophotometric and potentiometric data which can be used as a transfer function between the two properties. Spectrophotometric titrations are then used to determine the changes of humic acid protonation after adsorption onto $\alpha$-alumina.
\end{abstract}

\section{KEYWORDS}

Spectrophotometry; potentiometry; titration; humic acid; organic matter; sorption; salt effect

\section{BRIEFS}

Acid-base spectrophotometric titrations of humic acid are performed to assess humic proton binding groups at environmental concentrations. An operational transfer function is proposed to link spectroscopic changes to site densities variations as determined by acid-base potentiometric titrations. 


\section{Introduction}

Speciation and migration of metals in the environment are partly controlled by their interactions with natural organic matter (NOM) and minerals in soils $(1,2)$. In aquatic systems, whether an organic molecule partitions to mineral surfaces or remains dissolved determines in large its potential transport and susceptibility to degradation (3). For instance, in major rivers of the world $90 \%$ of transported organic matter is either adsorbed to fine minerals or remains dissolved $(4,5)$. A better description of ternary metal-NOM- surface systems is needed to improve the understanding of the behavior of metals.

Due to its heterogeneous nature, the composition and chemical properties of NOM are modified during adsorption onto mineral oxides (6-12). Previous investigations $(13,14)$ suggest that the NOM fractions of higher molecular weight, greater aromatic and carboxyl functional groups content, and more hydrophobic show preferential adsorption onto mineral oxides. This leads to modeling difficulties of the ternary systems (15, 16). A better knowledge of HS binding moieties modifications after partitioning on mineral surface is necessary to describe the behavior of metals in ternary systems.

Humic substances (HS), mainly composed of humic and fulvic acids are a prominent part of NOM, and are often used as surrogates of NOM. One of the most accurate ways to quantify HS functional groups is potentiometric titration, generally performed at a high concentration, i.e., c > $500 \mathrm{mg}_{\text {нА }} / \mathrm{L}$, to obtain a signal significantly different from background electrolyte titrations. These solution conditions are often unrealistic when compared to concentrations of dissolved organic carbon (DOC) in natural waters, i.e., 0.1 to 50 $\mathrm{mg}_{\mathrm{DOC}} / \mathrm{L}$, and much greater than those of HS in the supernatant of NOM adsorption experiments (612). It is necessary to consider an alternative technique to obtain proton binding data of NOM under realistic environmental concentrations.

HS solutions are colored and absorb UV and visible light. UV-Visible spectra of HS solutions, even though they tend to be rather featureless (17), may help to characterize HS sorption-fractionation processes $(11,18)$. Subtle changes in HS spectra induced by varying physico-chemical conditions have been used in differential absorbance spectroscopy to characterize HS $(19,20)$, and to interpret titration data of fulvic acids in dilute solution, e.g., $5 \mathrm{mg}_{\mathrm{DOC}} / \mathrm{L}$ (21). These spectrophotometric titrations allow examining the evolution of absorbance spectra with changes in $\mathrm{pH}$. HS light-absorbing functional groups, or chromophores, are deemed to typically contain conjugated double bonds and aromatic rings. The deprotonation of chromophores at increasing $\mathrm{pH}$ causes modification of the chromophores' absorbance spectra and/or formation of new absorbing centers and leads to a progressive modification of their absorbance properties. In contrast, potentiometric titrations determine the development of the sample charge within the $\mathrm{pH}$ range. So far, no attempt has been made to directly link the evolution of NOM absorbance signal to the change in charge with changes in $\mathrm{pH}$.

The aim of this study is to investigate the possible link between these two phenomena, even an operational one. The functional groups determined by potentiometry are composed of, bound to, or in close vicinity of the HS molecules chromophores. It seemed then possible to find a transfer function 
between variations of sample charge and solution absorbance. Previous studies have pointed to the importance of HS conformations that are affected by ionic strength on spectroscopic measurements (22, 23). Variations of molar extinction coefficients and chromism effect (24) depend both on chemical parameters of the solution and the HS studied. These variations must be accounted when relating potentiometric and spectrophotometric measurements.

Hereafter, spectrophotometric titrations at different ionic strengths were used to examine the deprotonation of purified Aldrich humic acid. The results were compared with those obtained from potentiometric titrations, in order to validate the spectroscopic method to characterize humic acid reactivity in solutions under environmental conditions and to determine a relationship between results of both methods for this humic acid. A spectrophotometric titration of a supernatant from a HS sorption experiment on $\alpha$-alumina was also performed under environmentally realistic conditions to test the methodology and to probe the acido-basic properties variation.

\section{Materials and methods}

\section{Preparation of samples}

Commercial Aldrich humic acid was purified (PAHA) according to ref. (25). Stock suspension at $2.5 \mathrm{~g}_{\mathrm{DOC}} / \mathrm{L}$ was prepared by diluting PAHA in $\mathrm{NaOH}$ (pH around 10) to completely dissolve the sample. In this work, concentrations of PAHA solutions, noted in $\mathrm{g} / \mathrm{L}$, always correspond to $\mathrm{g}_{\text {DOC }} / \mathrm{L}$. Alumina $\left(\alpha-\mathrm{Al}_{2} \mathrm{O}_{3}\right)$ was purchased from Interchim (pure 99.99\%, size fraction 200-500 nm). The solid was washed thrice with carbonate-free
$\mathrm{NaOH}$ and thrice with Millipore water before drying and storage at room temperature under $\mathrm{N}_{2}$ atmosphere according to ref. (26).

\section{Potentiometric titrations}

All titrations were performed using a computercontrolled system under $\mathrm{N}_{2}$ atmosphere, in a thermostated vessel $\left(25^{\circ} \mathrm{C}\right)$ equipped with a magnetic stirrer, at a HA concentration equal to $0.5 \mathrm{~g} / \mathrm{L}$. Ionic strength $(I)$ was fixed using $\mathrm{NaClO}_{4}(0.01$, 0.1 , and $0.5 \mathrm{~mol} / \mathrm{L})$. The quoted ionic strengths are the initial values before the addition of any titrant. In data analyses, actual $I$ was calculated for every data point, accounting both background electrolyte ions and free $\mathrm{H}^{+}$and $\mathrm{OH}^{-}$. The $\mathrm{pH}$ values of the solutions were controlled during titrations by addition of $0.1 \mathrm{~mol} / \mathrm{L}^{\mathrm{HClO}_{4}}$ and $\mathrm{NaOH}$ solutions. Base titrant (titrisol for $0.1 \mathrm{~mol} / \mathrm{L}$ solution) was prepared with degassed Millipore water. The $\mathrm{pH}$ values were recorded with two $\mathrm{pH}$ Metrohm 6.0133.100 glass electrodes and a single Metrohm 6.0733.100 reference electrode. The reference electrode was connected to the reaction vessel via an electrolyte bridge filled with $\mathrm{NaCl}$ at the background electrolyte concentration to prevent $\mathrm{KClO}_{4}$ precipitation in the system. The $\mathrm{pH}$ electrodes were calibrated by performing a blank titration of the background electrolyte prior to the sample titration. The aqueous suspension was purged with $\mathrm{N}_{2}$ at $\mathrm{pH}=3$ for 4 hours. The suspension was then titrated by adding small volumes of titrant and $\mathrm{pH}$ was recorded as a function of the titrant volume added to the suspension. After each addition, a drift criterion for $\mathrm{pH}$ was used $(\Delta \mathrm{mV} / \mathrm{min}<0.05)$ and a maximum time of 15 minutes was set for acquiring each data point. A similar procedure was followed for the blank solution titration. Three 
forward and backward titrations were done to eliminate the hysteresis effect (27).

\section{Absorbance measurements}

Absorbance titrations. After potentiometric titrations, solutions were diluted in background electrolyte to obtain $100 \mathrm{ml}$ of solution at a concentration of $5 \mathrm{mg} / \mathrm{L}$ in a thermostated vessel at $25^{\circ} \mathrm{C}$. After acid addition ( $\left.\mathrm{pH} 3\right)$, the solution was $\mathrm{N}_{2}$-purged for 1 hour. The $\mathrm{pH}$ was increased by addition of $\mathrm{NaOH}$ at 0.01 or $0.1 \mathrm{~mol} / \mathrm{L}$.

Absorbance spectra were recorded in a $5 \mathrm{~cm}$ quartz cuvette at circa $0.5 \mathrm{pH}$ intervals between pH 3 and 11 using a Thermo Evolution 600 UV/ Visible spectrophotometer between 190 and 600 $\mathrm{nm}$. UV/Visible spectra were recorded at room temperature $\left(25 \pm 4^{\circ} \mathrm{C}\right)$. It was checked that variations of temperature between 15 and $35^{\circ} \mathrm{C}$ had no influence on solution absorption (data not shown). The final data were corrected for dilution effects due to acid or base additions.

\section{Influence of ionic strength on solution $a b$ -} sorbance. To study the influence of $I$ on absorbance of the solution, $500 \mathrm{~mL}$ of a $5 \mathrm{mg} / \mathrm{L}$ PAHA solution at $I=5 \mathrm{mmol} / \mathrm{L} \mathrm{NaClO}_{4}$ was made, and acidified with $\mathrm{HClO}_{4}(0.1 \mathrm{~mol} / \mathrm{L})$ to $\mathrm{pH} 3.50$ mL-aliquots from this solution were sampled and weighted solid $\mathrm{NaClO}_{4}$ was added in each sample to obtain solutions with electrolyte concentrations of $0.01,0.05,0.1,0.2,0.3,0.4$ and $0.5 \mathrm{~mol} / \mathrm{L} \mathrm{Na}-$ $\mathrm{ClO}_{4}$. The $\mathrm{pH}$ values were adjusted if needed, and absorbance spectra were recorded.

\section{Adsorption experiment}

Three solutions of $10 \mathrm{~g} / \mathrm{L} \alpha-\mathrm{Al}_{2} \mathrm{O}_{3}$ and $100 \mathrm{mg} / \mathrm{L}$ PAHA, $I=0.1 \mathrm{~mol} / \mathrm{L} \mathrm{NaClO}_{4}$ and adjusted to $\mathrm{pH} 6$, were made in $10.4 \mathrm{ml}$ polycarbonate Beckman centrifugation tubes (41121703). After 5 days of equilibration, the solutions were ultra-centrifuged at 60,000 rpm for 2 hours. The supernatants were mixed and the solution was diluted in $0.1 \mathrm{~mol} / \mathrm{L}$ $\mathrm{NaClO}_{4}$ to obtain a $100-\mathrm{mL}$ solution of $5 \mathrm{mg} / \mathrm{L}$, which was then titrated using the spectrophotometric method previously described. PAHA concentration in the supernatant was measured using Shimadzu TOC-VCSH analyzer and was $26.5 \%$ of the initial content of PAHA.

\section{Results and Discussion}

\section{Potentiometric titrations}

Results of PAHA titrations are shown in Figure S1 of the Supporting Information (SI), together with the fits obtained by the NICA-Donnan model (28). In this model, the median affinities constants $\left(\log \mathrm{K}_{\mathrm{i}}\right)$, and the heterogeneity of distribution $\left(\mathrm{m}_{\mathrm{i}}\right)$ for the two main types of binding sites of humic acid (low-affinity, or so-called carboxylic, and high-affinity of so called phenolic groups) are fitted. The electrostatic parameters are obtained using the Master Curve procedure (27), optimizing the Donnan parameter $b$ in order to merge the original curves. The $\mathrm{pH}$ values were corrected for concentrations of protons using Davies equation (29).

The optimization of NICA-Donnan parameters for the titration curves was calculated using ECOSAT and FIT software $(30,31)$. Modeling parameters are given in Table 1, together with the ones used by Vermeer (15) and Milne et al. (32) for Aldrich humic acid. Differences between modeling of the same humic acid used in several studies can be due to (i) range of $I$ studied, (ii) differ- 
Table 1. NICA-Donnan modeling parameters for PAHA potentiometric titration and calculated charge from absorbance measurements after retention experiment.

\begin{tabular}{|c|c|c|c|c|c|c|c|c|}
\hline & $\log K_{1}$ & $\mathbf{m}_{1}$ & $\mathbf{Q}_{1}$ & $\log K_{2}$ & $\mathbf{m}_{2}$ & $\mathbf{Q}_{2}$ & $\mathbf{Q}_{0}$ & b \\
\hline HH18 (32) & 3.76 & 0.55 & 2.94 & 8.07 & 0.24 & 2.40 & & 0.69 \\
\hline HH24 (32) & 2.87 & 0.89 & 2.31 & $\begin{array}{l}8.00 \\
\text { (fixed) }\end{array}$ & 0.14 & 5.34 & & 0.25 \\
\hline PAHA (44) & 4.03 & 0.44 & 3.74 & 8.48 & 0.53 & 1.30 & & \\
\hline this study & 2.66 & 0.81 & 3.24 & 6.90 & 0.29 & 2.88 & 0.60 & 0.4 \\
\hline $\begin{array}{l}\text { PAHA after fractionation onto } \alpha \text { - } \\
\qquad \mathrm{Al}_{2} \mathrm{O}_{3}(\mathrm{R}=10 \mathrm{mg} / \mathrm{g})\end{array}$ & 2.90 & 0.85 & 1.61 & 8.00 & 0.25 & 20 & 0.29 & 0.4 \\
\hline
\end{tabular}

ences of the background electrolyte used, and (iii) differences in the stock and purification procedure. Our parameters are however within the range of those obtained previously.

\section{Spectrophotometric titrations}

PAHA absorbance spectra (see insert in Figure 1) show a broad and featureless shape characteristic of HS absorbance spectra throughout the $\mathrm{pH}$ range (17). The absorbance is increasing with the

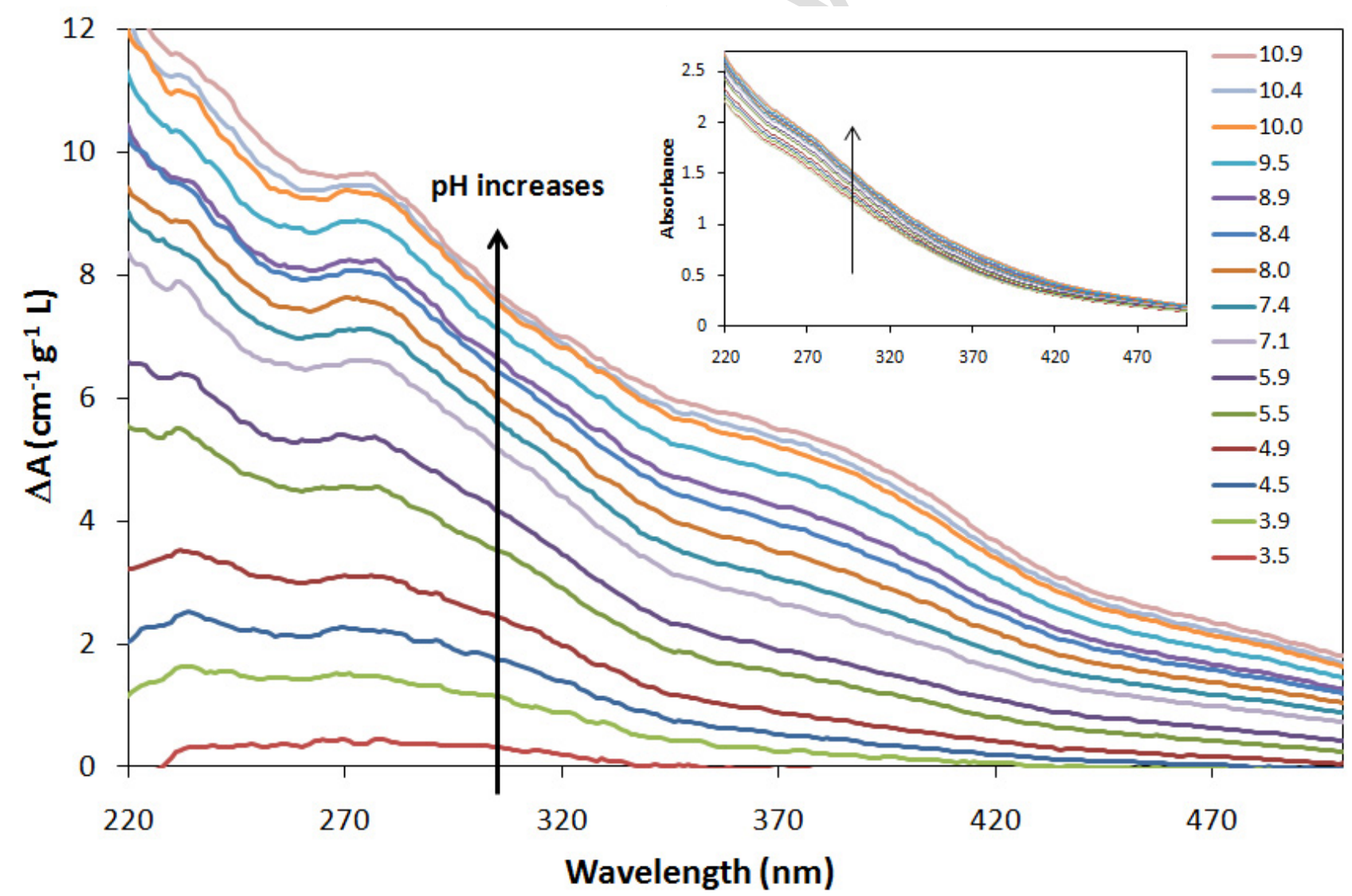

Figure 1. Differential absorbance spectra of PAHA in $0.1 \mathrm{~mol} / \mathrm{L} \mathrm{NaClO}_{4}\left(\mathrm{pH}_{\mathrm{ref}}=2.9\right)$. The original absorbance spectra are shown in the insert. 
solution $\mathrm{pH}$ due to the progressive deprotonation of the chromophores and change in structure (21). The solution at $\mathrm{pH} \approx 11$ absorbs around $10 \%$ more than the same solution at $\mathrm{pH} \approx 3$. Differential absorbance spectra were calculated using the following equation

$$
\Delta A_{p H}(\lambda)=\frac{1}{l_{\text {cell }}}\left[\frac{A_{p H}(\lambda)}{D O C}-\frac{A_{p H_{r e f}}(\lambda)}{D O C_{r e f}}\right]
$$

where $l_{\text {cell }}$ is the cell length $(\mathrm{cm}), D O C$ and $D O C_{\text {ref }}(\mathrm{mg} / \mathrm{L})$ are the dilution-corrected concentrations of DOC in the solution at the $\mathrm{pH}$ of interest and at the chosen reference $\mathrm{pH}$, respectively. $A(\lambda)$ and $A(\lambda)$ are the absorbance values measured at a given wavelength $\lambda$ at the $\mathrm{pH}$ of interest and at the reference $\mathrm{pH}$, respectively.

The spectrum recorded at the lowest $\mathrm{pH}$ value, i.e., $\mathrm{pH}_{\mathrm{ref}} \approx 3$, is used as a reference to examine the evolution of differential spectra throughout the en- tire $\mathrm{pH}$ range, according to ref. (21). Specific features appear in the differential spectra when the solution $\mathrm{pH}$ was increased from 3.5 to 10.9 (see Figure 1), such as the large band centered at 370 $\mathrm{nm}$ and the peak centered at $270 \mathrm{~nm}$. This latter peak corresponds to the UV region where the $\pi-\pi^{*}$ electron transition occurs for example for phenolic substances and polycyclic aromatic hydrocarbons (33), and so become more important with the deprotonation of the aromatic moieties of PAHA. The broad band at $370 \mathrm{~nm}$ and higher wavelengths is similar to the feature observed in the $\mathrm{pH}$-differential spectra of Suwannee River fulvic acid (21). This feature appears to be specific to humic species and can be hypothesized to be associated with inter-chromophore interactions, in accord with observation made in prior publications (22). However, its exact nature remains to be ascertained.

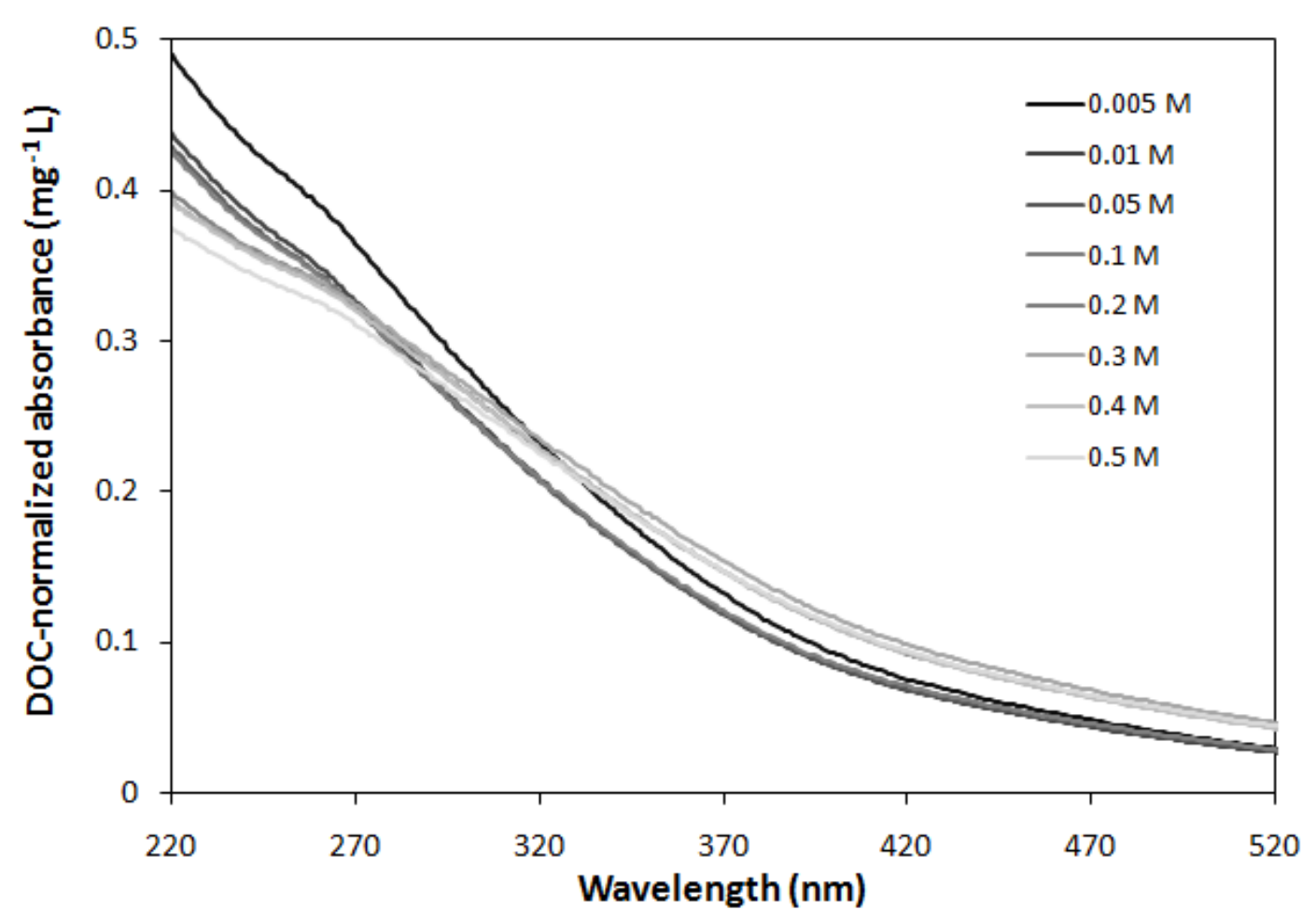

Figure 2. DOC-normalized absorbance spectra of PAHA solutions $(\sim 5 \mathrm{mg} / \mathrm{L})$ at $\mathrm{pH} 3, I=0.005-0.5$ $\mathrm{mol} / \mathrm{L} \mathrm{NaClO}_{4}$. 
Figure 2 shows the DOC-normalized ab- ionic strength will have a minor influence on the sorbance spectra of PAHA solutions at variable $I$, signal at the reference $\mathrm{pH}$. The fundamental reafrom $510^{-3}$ up to $0.5 \mathrm{~mol} / \mathrm{L} \mathrm{NaClO}_{4}$, and sons behind this behavior are surely hiding within $\mathrm{pH}=3.0 \pm 0.1$. There are two main groups: one corresponding to curves with $I$ ranging from 0.01 to $0.1 \mathrm{~mol} / \mathrm{L}$, and the second corresponding to $I$ ranging from 0.2 to $0.5 \mathrm{~mol} / \mathrm{L} \mathrm{NaClO}_{4}$. Except for the lowest $I$, a trend can be seen. For wavelengths below $270 \mathrm{~nm}$, the signal decreases with increasing $I$, whereas for wavelengths above $270 \mathrm{~nm}$, the signal increases with $I$, but with no differences inside the two groups. Spectrophotometric titrations and modeling were then studied at this specific wavelength since (i) it was the wavelength for which most important feature was observed, and (ii) the modifications of HS structure but it is outside the scope of this study.

Titration curves were built using the values of differential absorbance at $270 \mathrm{~nm}$ versus protons concentration in the Donnan phase $\left[\mathrm{H}^{+}\right]_{\mathrm{D}}$. They showed the differential absorbance increase with $\mathrm{pH}$ and $I$ (Figure 3). Plotting those curves against $\left[\mathrm{H}^{+}\right]_{\mathrm{D}}$ did not result into a Master Curve in this case: there was still an effect of $I$ on the absorbance of solution with $\mathrm{pH}$. This suggests the presence of an additional effect of $I$ on the conformation of PAHA that influenced the spectroscopic

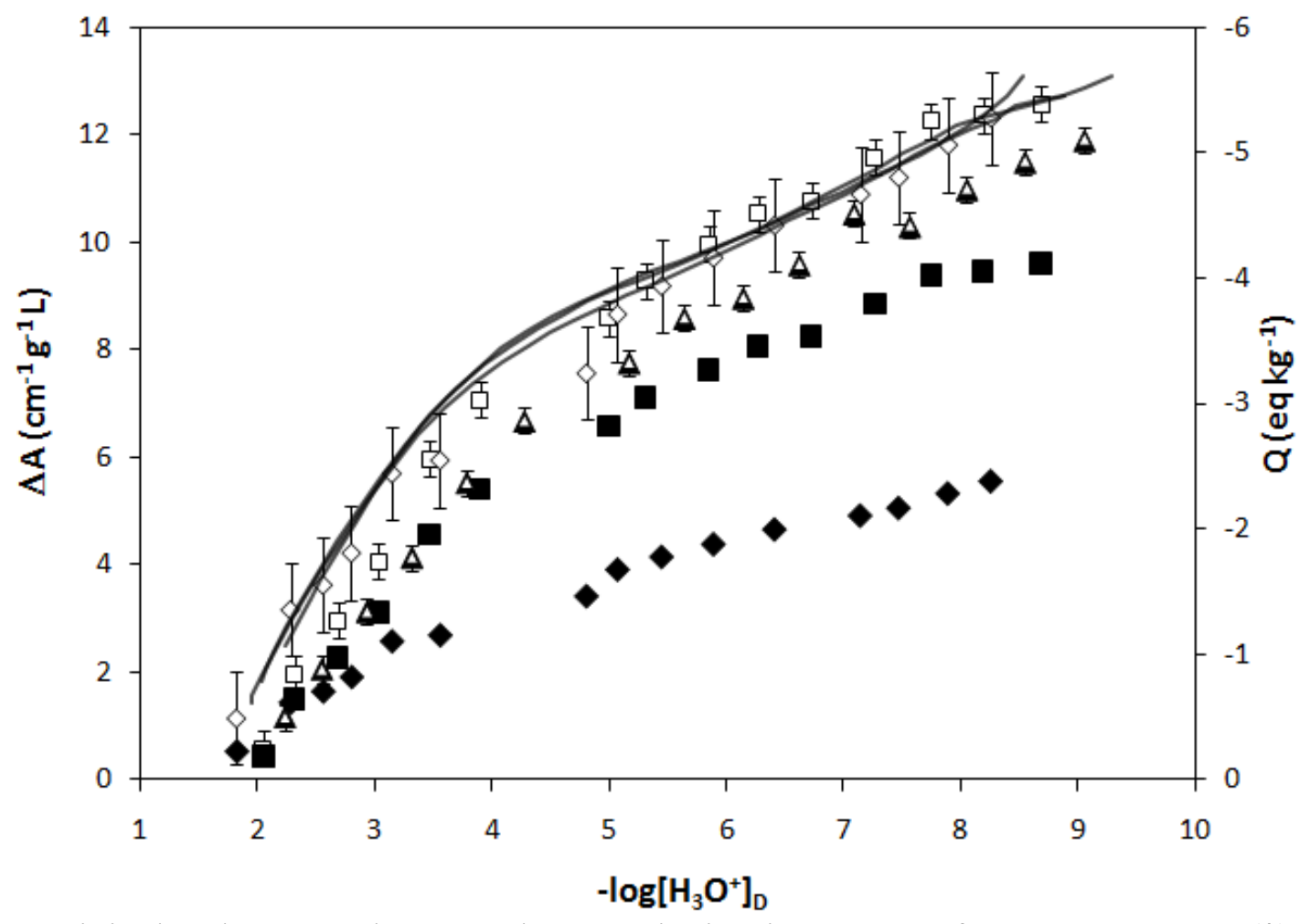

Figure 3. Original and corrected spectrophotometric titration curves of PAHA at $I=0.01(\diamond), 0.1(\square)$, and $0.5(\triangle) \mathrm{mol} / \mathrm{L} \mathrm{NaClO}_{4}$.

Results are plotted against the concentration of protons in the Donnan gel $\left[\mathrm{H}_{3} \mathrm{O}^{+}\right]_{\mathrm{D}}$. The close symbols are the original data. The open symbols are the data corrected from electrostatic component $(0.5 \mathrm{~mol} / \mathrm{L}$ being the reference for correction, both curves are stacked). The lines are the Master Curve from the potentiometric titrations (on the right axis). 
response of the solution, to which potentiometric titrations were not sensitive.

The results shown in Figure 3 suggest that PAHA mass absorptivity increases with electrolyte concentration. Nevertheless, the interactions between chromophores, leading to a modification of absorbance of the solution, or chromism, must be taken into account. Hyperchromism, i.e., increase of molecular absorptivity, can be explained by interactions between neighboring or stacked chromophores, enhancing energy and electrons transfer between donors and acceptors (24). This is consistent with previous observations that humic molecules tend to undergo aggregation at higher ionic strength, when the electrostatic double layer is more compressed $(23,34)$.

\section{Modeling}

To model the data, NICA parameters $\left(\mathrm{m}_{\mathrm{i}}, \log \right.$ $\mathrm{K}_{\mathrm{i}}$ ) of PAHA obtained by potentiometric titrations were used. The electrostatic effects were accounted by the Donnan model, using the concentration of protons into the Donnan gel at given $\mathrm{pH}$ $\left[\mathrm{H}^{+}\right]_{\mathrm{D}}$ and at the reference $\mathrm{pH}\left[\mathrm{H}^{+}\right]_{\text {Dref }}$. The absorbance titration curves were modeled using the following equation, derived from the NICA equation:

$\begin{aligned} \Delta A_{p H}(\lambda) & =\left|\begin{array}{l}A_{1}(\lambda) \frac{\left(\widetilde{K}_{1}\left[H^{+}\right]_{D}\right)^{m_{1}}}{1+\left(\widetilde{K}_{1}\left[H^{+}\right]_{D}\right)^{m_{1}}}-A_{1}(\lambda) \frac{\left(\widetilde{K}_{1}\left[H^{+}\right]_{D r e f}\right)^{m_{1}}}{1+\left(\widetilde{K}_{1}\left[H^{+}\right]_{D r e f}\right)^{m_{1}}} \\ +\mid A_{2}(\lambda) \frac{\left(\widetilde{K}_{2}\left[H^{+}\right]_{D}\right)^{m_{2}}}{1+\left(\widetilde{K}_{2}\left[H^{+}\right]_{D}\right)^{m_{2}}}-A_{2}(\lambda) \frac{\left(\widetilde{K}_{2}\left[H^{+}\right]_{D r e f}\right)^{m_{2}}}{1+\left(\widetilde{K}_{2}\left[H^{+}\right]_{D r e f}\right)^{m_{2}}}\end{array}\right|\end{aligned}$

The only optimized parameters are $A_{1}(\lambda)$, and $\mathrm{A}_{2}(\lambda)$, which represent the maximum change of absorbance of two mains groups of chromophores of low and high affinity for protons. These values depend on the chosen wavelength for modeling, here $270 \mathrm{~nm}$. For sake of clarity, they will be henceforth denoted as $A_{1}$ and $A_{2}$ instead of $A_{1}(270 \mathrm{~nm})$ and $A_{2}(270 \mathrm{~nm})$. Figure $S 2$ represents the titration curve with the respective influence of the two main groups of chromophores, and the result of modeling for the experiment at $0.1 \mathrm{~mol} / \mathrm{L}$ $\mathrm{NaClO}_{4}$.

As shown in Figure 4, the overall maximum change of absorbance by the two main groups of chromophores increased linearly with $\log I$, with parameters of linear regression being dependent on modeling wavelength. The conformation of humic acid, which changes with the concentration of electrolyte ions, had an influence on the absorbance of these solutions. But the proportion of the two mains groups of chromophores did not change significantly: within uncertainties and remained the same for all of the ionic strength studied (Table S1).

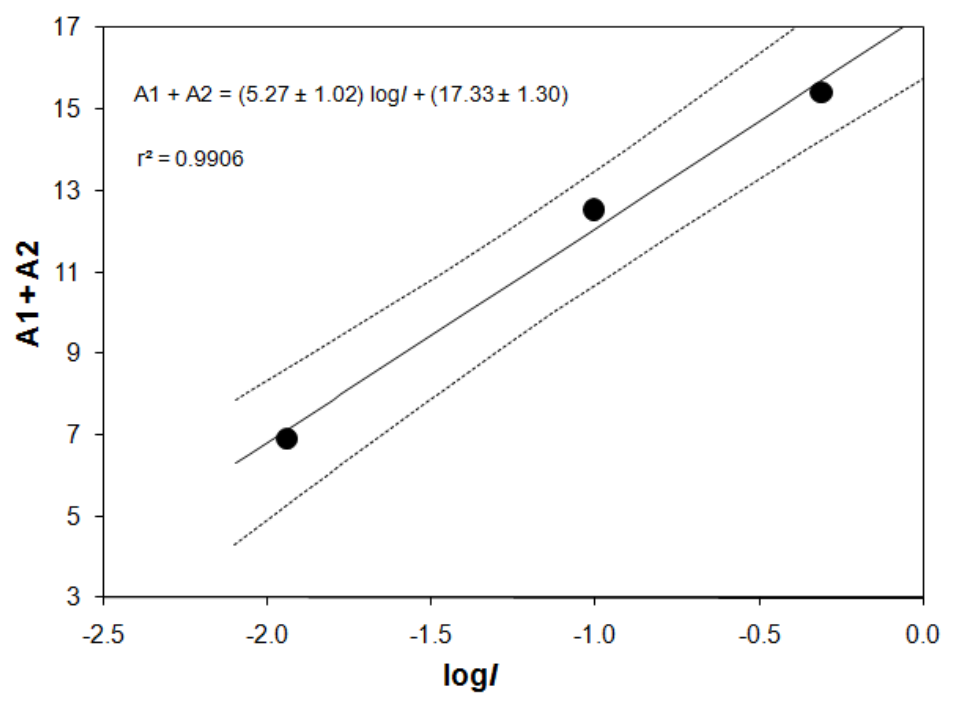

Figure 4. Comparison of the evolution of maximal absorbance $\mathrm{A}_{1}+\mathrm{A}_{2}$ as a function of $\log I$.

The continuous line is the result of the linear regression and the dotted ones the statistical envelope $\left(A_{1}+A_{2}\right) \pm \sigma\left(A_{1}+A_{2}\right)$. 


\section{Comparison of methods}

Modeling of potentiometric and spectrophotometric titration curves gave the same distribution of binding sites as seen in Table S1. In both cases, around $51 \%$ of signal was due to low affinity-type groups, and $49 \%$ to high affinity-type groups.

An additional correction was needed to account for the effect of $I$ on the spectroscopic signal in addition to the Donnan correction. Data at low $I$ were corrected to include results at the higher electrolyte concentration $\left.(0.5 \mathrm{~mol} / \mathrm{L} \mathrm{NaClO})_{4}\right)$, for which the effects of counter ions in the double layer was minimal and had less influence on the solution absorptivity. In the range of $I$ studied here $(0.01$ to $0.5 \mathrm{~mol} / \mathrm{L})$ there is a linear relationship between the sum of maximal change of absorbance of both types of groups $\left(\mathrm{A}_{1}+\mathrm{A}_{2}\right)$ and $\log I$ as shown in Figure 4: $\mathrm{A}_{1}+\mathrm{A}_{2}=c \log (I)+d$, with $c$
$=5.27 \pm 1.02$ and $d=17.33 \pm 1.30$. The correction factor $\mathrm{f}_{I}$ was calculated from this linear regression.

$$
f_{I}=\frac{c \log (0.5)+d}{c \log (I)+d}
$$

This correction, suitable in the range of $I$ studied in this study, was then applied to the differential absorbance values:

$$
(\Delta A)_{I, \text { corr }}=f_{I}(\Delta A)_{I}
$$

The corrected titration curves plotted against $\left[\mathrm{H}^{+}\right]_{\mathrm{D}}$ collapsed rather well into a single titration curve independent from ionic strength like for the Master Curve of potentiometric titrations, as shown in Figure 3.

Figure 5 shows charge versus electrostatic-corrected differential absorbance values at $270 \mathrm{~nm}$ for the same concentrations of protons and the three ionic strengths. There is a linear relationship between both properties. The linear regression of $\Delta \mathrm{Q}$

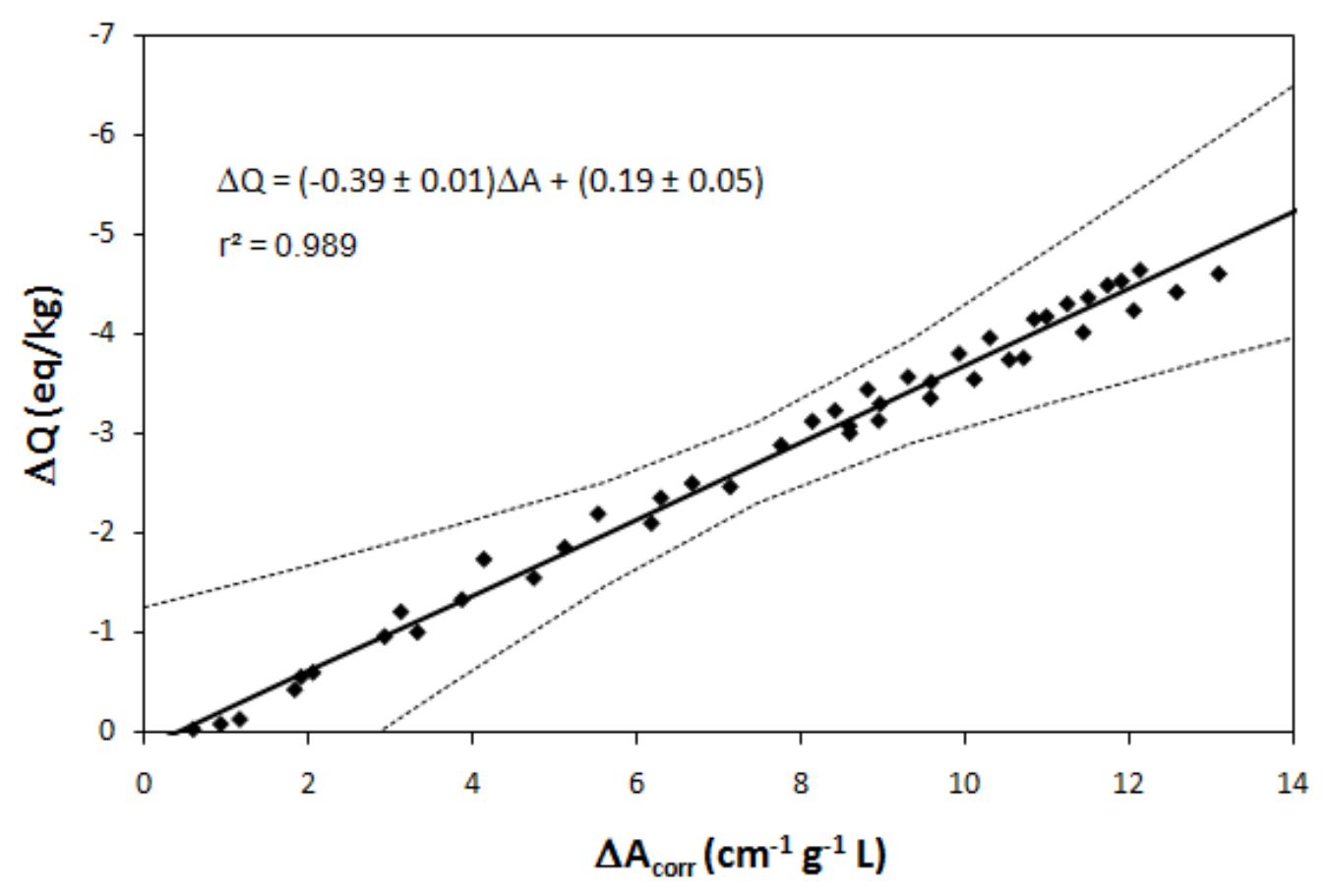

Figure 5. Comparison between charge and corrected differential absorbance for PAHA at same concentration of protons for the three studied $I$. The continuous line is the result of the linear regression and the dotted ones are the statistical envelope $\mathrm{Q} \pm \sigma \mathrm{Q}$. 
vs. $\Delta \mathrm{A}_{\text {corr }}$ gave a slope of $-0.367 \pm 0.003$. This is the transfer function between spectrophotometric and potentiometric titrations for PAHA, at $270 \mathrm{~nm}$. This proportionality is observed in the case of PAHA, for both titrations performed with the same stability constraints and under free- $\mathrm{CO}_{2}$ conditions and should be established for other HS samples. Measurements should be made on purified samples only to avoid interferences with particles and inorganic species that absorb light in UV range as metals and nitrate ions.

Here again, the fundamental reasons behind this simple relationship remain unclear. Also one should note that the relative uncertainties in the obtained $\Delta \mathrm{Q}$ from the measured $\Delta \mathrm{A}$ remain important. The modifications of the chemical environment of the chromophores absorbing around $270 \mathrm{~nm}$ with $\mathrm{pH}$ and ionic strength is clearly at stakes. Nevertheless, this operational relationship could be used for this sample.

Application to PAHA after adsorption onto $\alpha-$ $\boldsymbol{A l}_{2} \boldsymbol{O}_{3}$. It seems possible, using spectrophotometric titrations, to study fractions of PAHA in the supernatant of retention experiments to quantify modifications of PAHA binding moieties due to the contact with the mineral surface. This exercise should be viewed as a test for the operational relationship under conditions outside its domain of calibration.

The results of differential absorbance spectra of the supernatant are shown in Figure 6. The loss of proton binding sites, as well as the modification of the different features of the differential absorbance spectra, are clearly visible, especially the loss of the broad range around $370 \mathrm{~nm}$ and the rising of the peak centered at $270 \mathrm{~nm}$. Titration curve has been built, and corrected from electrostatic effects using equations (3) and (4) as described above

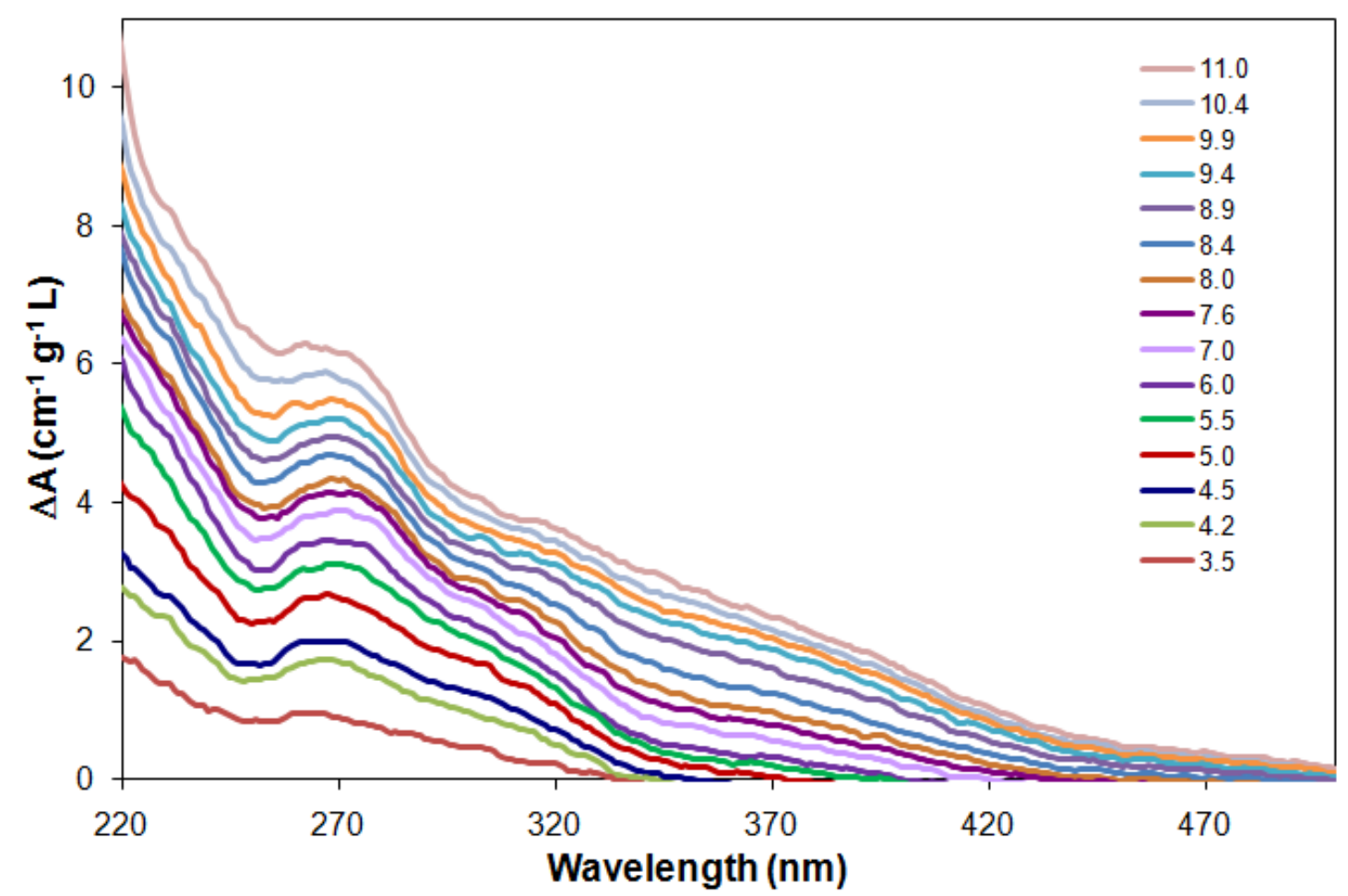

Figure 6. Differential absorbance spectra of PAHA in $0.1 \mathrm{~mol} / \mathrm{L} \mathrm{NaClO}$ after fractionation onto $\alpha-\mathrm{Al}_{2} \mathrm{O}_{3}$ $(\mathrm{R}=10 \mathrm{mg} / \mathrm{g})$. 
(see Figure S3). The charge of non-sorbed PAHA $\mathrm{Q}_{\mathrm{R} 20}$ was calculated from corrected spectrophotometric titration curve using the linear $\Delta \mathrm{Q}$ vs. $\Delta \mathrm{A}_{\text {corr }}$ equation obtained previously.

The NICA-Donnan parameters for PAHA fraction generated in the adsorption experiment were optimized using FIT and ECOSAT software (30, 31) and given in Table 1.

Within this approach, it appears that there is no need to greatly modify the heterogeneity parameters $\mathrm{m}_{\mathrm{i}}$ before and after sorption, but a shift of the median affinity constants towards higher $\mathrm{pH}$ is required for the non-sorbed sample.

During the retention experiment, carried out at $\mathrm{pH} 6$, around $61 \%$ of sites of non-sorbed PAHA are deprotonated: $52 \%$ of low affinity-type sites and $9 \%$ of high affinity-type sites. The former should have been more attracted by the surface than the latter. The modeling suggests a general loss of $50 \%$ of low affinity-type sites and $17 \%$ of high affinity-type sites after contact with the oxide. This suggests, within the validity limit of the transfer function, that fractions of PAHA molecules that have stayed on the surface contained mostly all of ionized low affinity-type sites and a greater proportion of high-affinity sites than their ionized proportion. Low affinity-type sites are not only composed of aliphatic but also of benzoic including hydroxybenzoic compounds $(35,36)$, and the sorption data of HS and of phthalic $(37,38)$ or hydroxybenzoic acids $(39,40)$ on iron and aluminum (oxy)hydroxide extend largely after the $\mathrm{pK}$ of their first carboxylic function as it is the case for HS (41-43). One can thus understand that high-affinity-type sites are proportionally overrepresented on the surface as it was evidenced by Claret et al. (11).
Acknowledgment. This work was financed through the MRISQ (DEN/DISN/AvC) project of CEA. This is IPGP contribution 3049.

Supporting Information Available. One table and three figures show the results of potentiometric titrations of PAHA, the distribution of the influence of the two types of sites depending on $\mathrm{pH}$ for spectrophotometric titration at $0.1 \mathrm{~mol} / \mathrm{L} \mathrm{Na}$ $\mathrm{ClO}_{4}$, the difference of spectrophotometric titrations curves for PAHA that has been or not in contact with $\alpha-\mathrm{Al}_{2} \mathrm{O}_{3}$, and the quantification of the two types of sites for spectrophotometric and potentiometric titrations modeling.

\section{References}

(1) McCarthy, J. F.; Czerwinski, K. R.; Sanford, W. E.; Jardine, P. M.; Marsh, J. D., Mobilization of transuranic radionuclides from disposal trenches by natural organic matter. Journal of Contaminant Hydrology 1998, 30, (1-2), 49-77.

(2) McCarthy, J. F.; Sanford, W. E.; Stafford, P. L., Lanthanide field tracers demonstrate enhanced transport of transuranic radionuclides by natural organic matter. Environmental Science \& Technology 1998, 32, (24), 3901-3906.

(3) Aufdenkampe, A. K.; Hedges, J. I.; Richey, J. E.; Krusche, A. V.; Llerena, C. A., Sorptive fractionation of dissolved organic nitrogen and amino acids onto fine sediments within the Amazon Basin. Limnology and Oceanography 2001, 46, (8), 1921-1935.

(4) Meybeck, M., Carbon, Nitrogen, and Phosphorus transport by world rivers. American Journal of Science 1982, 282, (4), 401-450.

(5) Keil, R. G.; Mayer, L. M.; Quay, P. D.; Richey, J. E.; Hedges, J. I., Loss of organic matter from riverine particles in deltas. Geochimica Et Cosmochimica Acta 1997, 61, (7), 1507-1511.

(6) Gu, B.; Schmitt, J.; Chem, Z.; Liang, L.; McCarthy, J. F., Adsorption and desorption of natural organic matter on iron oxide: Mechanisms and models. Environmental Science \& Technology 1994, 28, 38-46.

(7) Hur, J.; Schlautman, M. A., Molecular weight fractionation of humic substances by adsorption onto minerals. Journal of Colloid and Interface Science 2003, 264, (2), 313-321. 
(8) Hur, J.; Schlautman, M. A., Effects of $\mathrm{pH}$ and phosphate on the adsorptive fractionation of purified Aldrich humic acid on kaolinite and hematite. Journal of Colloid and Interface Science 2004, 277, (2), 264270.

(9) Kaiser, K., Sorption of natural organic matter fractions to goethite (a-FeOOH): Effect of chemical composition as revealed by liquid-state C-13 NMR and wet-chemical analysis. Organic Geochemistry 2003, 34, (11), 1569-1579.

(10) Reiller, P.; Amekraz, B.; Moulin, C., Sorption of Aldrich humic acid onto hematite: Insights into fractionation phenomena by electrospray ionization with quadrupole time-of-flight mass spectrometry. Environmental Science \& Technology 2006, 40, (7), 22352241.

(11) Claret, F.; Schäfer, T.; Brevet, J.; Reiller, P. E., Fractionation of Suwannee River fulvic acid and Aldrich humic acids on $\alpha-\mathrm{Al}_{2} \mathrm{O}_{3}$ : spectroscopic evidence. Environmental Science \& Technology 2008, 42, (23), 8809-8815.

(12) Saito, T.; Koopal, L. K.; van Riemsdijk, W. H.; Nagasaki, S.; Tanaka, S., Adsorption of humic acid on goethite: Isotherms, charge adjustments, and potential profiles. Langmuir 2004, 20, (3), 689-700.

(13) Davis, J. A.; Gloor, R., Adsorption of dissolved organics in lake water by Aluminum-oxide - Effect of molecular weight. Environmental Science \& Technology 1981, 15, (10), 1223-1229.

(14) Day, G. M.; Hart, B. T.; McKelvie, I. D.; Beckett, R., Adsorption of natural organic matter onto goethite. Colloids and Surfaces a-Physicochemical and Engineering Aspects 1994, 89, (1), 1-13.

(15) Vermeer, A. W. P.; McCulloch, J. K.; van Riemsdijk, W. H.; Koopal, L. K., Metal ion adsorption to complexes of humic acid and metal oxides: Deviation from the additivity rule. Environmental Science \& Technology 1999, 33, (21), 3892-3897.

(16) Robertson, A. P.; Leckie, J. O., Humic acid/ goethite interactions and their effect on copper binding. In Humic substances in the global environment and implication on human health, Senesi, N.; Miano, T. M., Eds. Elsevier: 1994; pp 487-492.

(17) MacCarthy, P.; Rice, J. A., Spectroscopic methods (other than NMR) for determining functionality in humic substances. In Humic Substances in soil, sediment and water. Geochemistry, isolation, and characterisation, Aiken, G. R.; McKnight, D. M.; Wershaw, R.; MacCarthy, P., Eds. John Wiley and Sons: New York, 1985; pp 527-559.

(18) Korshin, G. V.; Li, C.-W.; Benjamin, M. M., Monitoring the properties of natural organic matter through UV spectroscopy: A consistent theory. Water Research 1997, 31, (7), 1787-1795.
(19) Ghosh, K.; Schnitzer, M., UV and visible absorption spectroscopic inverstigations in relation to macromolecular characteristics of humic substances. Journal of Soil Science 1979, 30, (4), 735-745.

(20) Korshin, G. V.; Benjamin, M. M.; Li, C. W., Use of differential spectroscopy to evaluate the structure and reactivity of humics. Water Science and Technology 1999, 40, (9), 9-16.

(21) Dryer, D. J.; Korshin, G. V.; Fabbricino, M., In situ examination of the protonation behavior of fulvic acids using differential absorbance spectroscopy. Environmental Science \& Technology 2008, 42, (17), 6644-6649.

(22) Del Vecchio, R.; Blough, N. V., On the origin of the optical properties of humic substances. Environmental Science \& Technology 2004, 38, (14), 38853891.

(23) Conte, P.; Piccolo, A., Conformational arrangement of dissolved humic substances. Influence of solution composition on association of humic molecules. Environmental Science \& Technology 1999, $33,(10), 1682-1690$.

(24) Vekshin, N. L., Screening hypochromism in chromophore stacks. Optics and Spectroscopy 1987, 63, 517-519.

(25) Kim, J. I.; Buckau, G.; Li, G. H.; Duschner, H.; Psarros, N., Characterization of humic and fulvic acids from Gorleben groundwater. Fresenius Journal of Analytical Chemistry 1990, 338, 245-252.

(26) Alliot, C.; Bion, L.; Mercier, F.; Toulhoat, P., Sorption of aqueous carbonic, acetic, and oxalic acids onto $\alpha$-alumina. Journal of Colloid and Interface Science 2005, 287, (2), 444-451.

(27) Milne, C. C. J.; Kinniburgh, D. G.; de Wit, J. C. M.; van Riemsdijk, W. H.; Koopal, L. K., Analysis of proton binding by peat humic acid using a simple electrostatic model. Geochimica et Cosmochimica Acta 1995, 59, 1101-1112.

(28) Kinniburgh, D. G.; van Riemsdijk, W. H.; Koopal, L. K.; Borkovec, M.; Benedetti, M. F.; Avena, M. J., Ion binding to natural organic matter: Competition, heterogeneity, stoichiometry and thermodynamic consistency. Colloids and Surfaces A 1999, 151, 147166.

(29) Davies, C. W., Ion Association. Butterworth: London, 1962.

(30) Keizer, M. G.; van Riemsdijk, W. H., A computer program for the Calculation of Chemical Speciation and Transport in Soil-Water Systems (ECOSAT 4.7). . Agricultural University of Wageningen: Wageningen, 1994.

(31) Kinniburgh, D. G. FIT Non-linear Optimization Algorithm and User Manual; British Geological Survey: Nottingham, UK, 1993. 
(32) Milne, C. J.; Kinniburgh, D. G.; Tipping, E., Generic NICA-Donnan model parameters for proton binding by humic substances. Environmental Science \& Technology 2001, 35, (10), 2049-2059.

(33) Chin, Y. P.; Aiken, G.; Oloughlin, E., Molecular weight, polydispersity, and spectroscopic properties of aquatic humic substances. Environmental Science \& Technology 1994, 28, (11), 1853-1858.

(34) Duval, J. F. L.; Wilkinson, K. J.; van Leeuwen, H. P.; Buffle, J., Humic substances are soft and permeable: evidence from their electrophoretic mobilities. Environmental Science \& Technology 2005, 39, 6435-6445.

(35) Moulin, V.; Reiller, P.; Amekraz, B.; Moulin, C., Direct characterization of iodine covalently bound to fulvic acids by electrospray mass spectrometry. Rapid Communications in Mass Spectrometry 2001, $15,(24), 2488-2496$.

(36) These, A.; Winkler, M.; Thomas, C.; Reemtsma, T., Determination of molecular formulas and structural regularities of low molecular weight fulvic acids by size-exclusion chromatography with electrospray ionization quadrupole time-of-flight mass spectrometry. Rapid Communications in Mass Spectrometry 2004, 18, (16), 1777-1786.

(37) Gu, B. H.; Schmitt, J.; Chen, Z.; Liang, L. Y.; McCarthy, J. F., Adsorption and desorption of different organic-matter fractions on iron-oxide. Geochimica Et Cosmochimica Acta 1995, 59, (2), 219-229.
(38) Ali, M. A.; Dzombak, D. A., Competitive sorption of simple organic acids and sulfate on goethite. Environmental Science \& Technology 1996, 30, (4), 1061-1071.

(39) Davis, J. A.; Leckie, J. O., Effect of adsorbed complexing ligands on trace-metal uptake by hydrous oxides. Environmental Science \& Technology 1978, 12, (12), 1309-1315.

(40) Evanko, C. R.; Dzombak, D. A., Influence of structural features on sorption of NOM-analogue organic acids to goethite. Environmental Science \& Technology 1998, 32, (19), 2846-2855.

(41) Varadachari, C.; Chattopadhyay, T.; Ghosh, K., Complexation of humic substances with oxides of iron and aluminum. Soil Science 1997, 162, (1), 28-34.

(42) Meier, M.; Namjesnik-Dejanovic, K.; Maurice, P. A.; Chin, Y. P.; Aiken, G. R., Fractionation of aquatic natural organic matter upon sorption to goethite and kaolinite. Chemical Geology 1999, 157, (3-4), 275-284.

(43) Reiller, P.; Moulin, V.; Casanova, F.; Dautel, C., Retention behaviour of humic substances onto mineral surfaces and consequences upon thorium (IV) mobility: case of iron oxides. Applied Geochemistry 2002, 17, (12), 1551-1562.

(44) Vermeer, A. W. P. Interaction between humic acid and hematite and their effects upon metal speciation. PhD Thesis. Landbouwuniversiteit Wageningen, Wageningen, The Netherlands, 1996. 